\title{
A AVALIAÇÃO EM PRÁTICA DE ENSINO DE INGLÊS NO CAp-UERJ: RELATÓRIO DE ESTÁGIO
}

\author{
João Bittencourt de Oliveira' ${ }^{1}$ \\ Marta Guimarães Caram²
}

CAP-UERJ

\section{RESUMO:}

A avaliação nas disciplinas de Prática de Ensino de Inglês e Estágio Supervisionado, ministrada por professores de inglês do CAp-UERJ no Instituto de Letras da UERJ, constitui nota de estágio atribuída pelo professor orientador (professor regente de turmas do CAp) e nota de relatório de estágio atribuída pelo professor supervisor (professor de Prática de Ensino). Não há reprovação, visto que o estagiário é levado a observar, praticar, co-participar, participar, e elaborar atividades, tantas vezes quanto necessário, para desenvolver suas habilidades no que concerne ao trabalho pedagógico. Por fim, o estagiário é orientado a redigir um relatório de estágio que é um trabalho acadêmico de final de curso, não só de caráter descritivo, mas também reflexivo, crítico. O grau de exigência é elevado, seja em nível de texto/discurso, seja em nível de normas acadêmicas. Esta apresentação focaliza principalmente os objetivos e formato desse relatório.

PalaVras-ChaVe: estágio - relatório - prática de ensino

\begin{abstract}
:
The evaluation in the disciplines of English Teaching Practice and Supervised Probation, delivered by the team of teachers of English of Cap-UERJ at the Institute of Letters of UERJ, constitutes grade for probation awarded by the tutorial teacher (the class teacher at CAp) and grade for probation report awarded by the supervising teacher (the teacher of Teaching Practice). There is no failure policy, considering that the probationary student is led to observe, practice, co-participate, participate, and elaborate activities, as many times as necessary, in order to develop his/her abilities regarding the pedagogical work. Finally, the probationary student is guided to draw up a probation report, which is a final course academic paper, not only of descriptive, but also of reflexive and critical character. The degree of exigency is high, whether at the text/discourse level, or at the level of academic norms. This presentation focuses mainly on the objectives and format of this report.
\end{abstract}

KEY WORDS: probation - probation report - teaching practice 
e-Mosaicos - Revista Multidisciplinar de Ensino, Pesquisa, Extensão e Cultura do Instituto de Aplicação Fernando Rodrigues da Silveira (CAp-UERJ)

ANO 1 - V. 1 - N. 1 - JUNHO 2012 - ISSN: 2316-9303

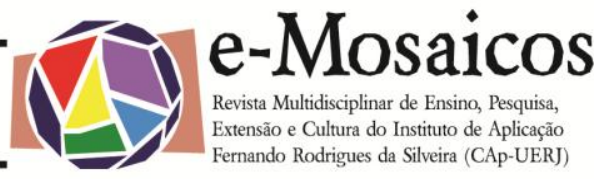

\section{INTRODUÇÃO}

No ILE (Instituto de Letras da UERJ Universidade do Estado do Rio de Janeiro), as disciplinas de Prática de Ensino e Estágio Supervisionado em Inglês ${ }^{1}$ são ministradas por professores do Departamento de Línguas e Literatura (DLL) do Instituto de Aplicação Fernando Rodrigues da Silveira, CApUERJ, e o estágio é feito no mesmo colégio, que é uma unidade acadêmica da Universidade. A avaliação dessas disciplinas tem valor qualitativo: não há reprovação, pois se espera que o aluno (estagiário) aprenda a aprender fazendo, ou seja, pratique o maior tempo possível as atividades que fazem parte da rotina de trabalho de um professor. É requisitado aos alunos que refaçam as atividades, pontuando questões de maior dificuldade para o estagiário, e as reapresentem ao professor orientador, aquele com quem atuam nas turmas de ensino fundamental e médio do CAp-UERJ.

O estagiário é avaliado pelo professor orientador em suas observações de aula, atividades de co-participação ou participação, e atividades complementares. Enquanto aluno de prática é avaliado pelo professor supervisor, que é aquele com quem tem aulas teóricas presenciais no campus do ILE, através de um relatório de estágio, que deverá ser apresentado ao final do curso, e considerado juntamente com a avaliação do professor orientador para obtenção da média final.

O relatório de estágio é o objeto principal de análise deste trabalho, pois é a etapa

\footnotetext{
${ }^{1}$ A estrutura das disciplinas de Prática de Ensino e Estágio Supervisionado ocorrerá até 2009. Em 2008 já estarão sendo oferecidas novas disciplinas concernentes à formação de professores, visto que a legislação assim o exige. Entretanto, a avaliação dos estagiários será mantida, sendo apenas adaptada ao novo currículo.
}

final da avaliação dos estagiários: seus objetivos, características, especificidades, etapas, os quais evidenciam o alto grau de qualidade exigido pelos professores supervisores. Para atender ao objetivo firmado, abordaremos o assunto em duas seções: na primeira trataremos, sucintamente, das etapas fundamentais do Estágio Supervisionado; na segunda detalharemos a etapa final do estágio - a redação do Relatório.

A verificação do desempenho do estagiário, como ressaltamos acima, será, pois, contínua e cumulativa, com prevalência dos aspectos qualitativos sobre os quantitativos e dos resultados ao longo do estágio sobre os de eventuais provas discursivas.

Conforme a natureza do trabalho desenvolvido, o estagiário será orientado a recorrer a métodos diferentes e às suas respectivas técnicas, como: métodos dedutivos (que se destinam a demonstrar e justificar), métodos indutivos (que se destinam a verificar a partir da observação e/ou da experimentação) e métodos fenomenológicos (que se preocupam com a descrição direta da experiência como ela é).

O objetivo deste trabalho é discutir como ocorre, na prática, a prevalência dos aspectos qualitativos sobre os quantitativos na avaliação do estágio supervisionado no CAp-UERJ.

Acreditamos, assim, que a elaboração das normas do Relatório em tela se justifica perante aqueles que compartilham conosco da visão do problema ora enfrentado pelo aluno de graduação sobre o trabalho de pesquisa, o desenvolvimento do hábito de estudo, da reflexão, do rigor da análise, da crítica e da documentação. 


\section{SOBRE O ESTÁGIO SUPERVISIONADO}

O estágio supervisionado no CAp-UERJ tem por objetivo capacitar o estagiário na aplicação prática dos fatos teóricos estudados na graduação e licenciatura, visando a favorecer seu desenvolvimento crítico e profissional. $O$ estágio atualmente acontece em quatro práticas: I, II, III e IV, assim distribuídas:

\begin{tabular}{|l|l|l|}
\hline Prática I & Co-participação & $6^{\circ}$ ao $8^{\circ}$ ano do E.F. \\
\hline Prática II & Participação & $6^{\circ}$ ao $8^{\circ}$ ano do E.F. \\
\hline Prática III & Co-participação & $9^{\circ}$ ano do E.F., $1^{\text {a }}$ a $3^{\mathrm{a}}$ série do E.M. \\
\hline Prática IV & Participação & $9^{\circ}$ anodo E.F., $1^{\mathrm{a}}$ a $3^{\mathrm{a}}$ série do E.M. \\
\hline
\end{tabular}

\subsection{As atividades da Prática de Ensino}

Há dois tipos de atividades: as de caráter obrigatório, (observações de aulas, coparticipações e participações) e as complementares.

As atividades desenvolvidas devem ser registradas na agenda do estagiário. A cada registro deverá corresponder uma rubrica: do professor orientador, no caso das obrigatórias, do professor regente, no caso das observações livres, e do professor supervisor, no caso das atividades extracurriculares e, ou das atividades diversificadas.

\subsection{As atividades obrigatórias}

Em cada uma das práticas o estagiário deverá cumprir 15 atividades de caráter obrigatório, conforme detalhadas no quadro abaixo:

\begin{tabular}{|l|l|l|}
\hline Práticas I e II & Atividades de Co-participação & Atividades de Participação \\
\hline \multirow{4}{*}{$6^{\circ}$ e $7^{\circ}$ anos do E.F. } & 6 Observações consecutivas & 6 Observações consecutivas \\
\cline { 2 - 3 } & 4 Co-participações consecutivas & 4 Participações consecutivas \\
\cline { 2 - 3 } & 5 Atividades complementares & 5 Atividades complementares \\
\hline \multirow{3}{*}{$8^{\circ}$ ano do E.F. } & 4 Observações consecutivas & 4 Observações consecutivas \\
\cline { 2 - 3 } & 2 Co-participações consecutivas & 2 Participações consecutivas \\
\cline { 2 - 3 } & 9 Atividades complementares & 9 Atividades complementares \\
\hline
\end{tabular}


e-Mosaicos - Revista Multidisciplinar de Ensino, Pesquisa, Extensão e Cultura do Instituto de Aplicação Fernando Rodrigues da Silveira (CAp-UERJ) ANO 1 - V. 1 - N. 1 - JUNHO 2012 - ISSN: 2316-9303

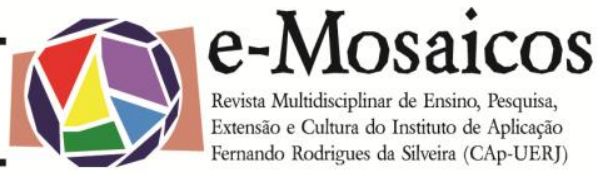

\begin{tabular}{|l|l|l|}
\hline Práticas II e IV & Atividades de Co-participação & Atividades de Participação \\
\hline \multirow{2}{*}{$\begin{array}{l}9^{\circ} \text { ano do E.F. ao } \\
3^{\circ} \text { ano do E.M. }\end{array}$} & 4 Observações consecutivas & 4 Observações consecutivas \\
\cline { 2 - 3 } & 2 Co-participações consecutivas & 2 Participações consecutivas \\
\cline { 2 - 3 } & 9 Atividades complementares & 9 Atividades complementares \\
\hline
\end{tabular}

\subsection{Conteúdo das atividades obrigató- rias}

As atividades obrigatórias se compõem de observações, co-participações e participações.

\subsubsection{As observações}

Há dois tipos de observações de aula: observações livres e obrigatórias.

As observações livres podem ser efetuadas em quaisquer das turmas cujos níveis correspondam àqueles das Práticas a que pertencem.

As observações obrigatórias são aquelas realizadas na turma fixa do estagiário, sob a supervisão do professor orientador do estágio no CAp-UERJ.

Para cada uma das observações livres, o estagiário deverá preencher a ficha de observação de aula. Dessa ficha constam:

1) Identificação do Estagiário.

2) Dados referentes ao CAp-UERJ: turma/grupo, horário; professor(a) regente, data.

3) Identificação do material didático.

4) Habilidade(s) desenvolvida(s).

5) Etapas da aula implementadas.

6) Análise do planejamento.

7) Fatores relevantes no processo ensinoaprendizagem: condições ambientais, relacionamento professor/alunos, relacionamento aluno/aluno, atitude disciplinar do grupo etc.

8) Objetivos atingidos.

9) Análise de exercício escrito e/ou prova.

10) Comentários adicionais. (ou (;) e minúscula).

O registro e rubrica na agenda do estagiário, pelas observações, somente serão efetuados mediante a apresentação da ficha de observação devidamente preenchida.

\subsubsection{As co-participações}

Além das observações obrigatórias, o estagiário deverá desenvolver coparticipações (Práticas I e III), e atividades complementares à sua co-participação, todas ligadas ao conteúdo programático da disciplina, e da escolha do professor orientador.

As co-participações envolvem:

a) montagem de exercício de fixação;

b) montagem de exercício de avaliação.

Constituem atividades complementares de co-participação:

a) elaboração de materiais auxiliares tais 
como jogos (com o devido rationale ${ }^{2}$, recursos visuais, flash cards, posters etc.;

b) elaboração e montagem de atividade de listening ou vídeo, utilizando materiais de fontes diversas (non-ELT ${ }^{3}$ ) tais como músicas, video clips, cenas de filmes, mas que tenham vínculo com o tema da unidade a que se refere e com a aula dada;

c) correção de exercício fora de sala com tabulação e análise de erros;

d) análise de provas ou testes;

e) elaboração de atividade de avaliação, com o devido gabarito;

f) reunião de planejamento do estágio;

g) reunião de avaliação do estágio.

\subsubsection{As participações}

Além das observações obrigatórias, o estagiário deverá desenvolver participações (Práticas II e VI) e atividades complementares à sua participação, todas ligadas ao conteúdo programático da disciplina, e da escolha do professor orientador.

Constituem atividades de participação:

a) implementação de aula inteira: motivação, apresentação, prática oral, escrita, monitoração de duplas / grupo (previamente agendada com o professor orientador);

b) elaboração do plano de aula, previamente discutido com o professor orientador;

a) ${ }^{2}$ Fundamento lógico; base racional; exposição de motivos.

b) ${ }^{3}$ non-ELT (English Language Teaching): Material não relacionado ao Ensino de Língua Inglesa.
c) elaboração e montagem de exercício de fixação;
d) elaboração e montagem de exercício de avaliação.

Constituem atividades complementares de participação:

a) reunião de planejamento do estágio;

b) reunião de avaliação do estágio;

c) pesquisa de materiais (textos, imagens, material fonográfico, visando a elaboração e montagem de atividade de reading, listening ou video comprehension);

d) elaboração de materiais auxiliares tais como jogos (com o devido rationale), recursos visuais, flash cards, posters etc;

e) elaboração de atividade de avaliação, com o devido gabarito;

f) correção de exercício fora de sala com tabulação e análise de erros;

g) elaboração e montagem de atividade de listening ou video utilizando materiais de fontes diversas (non-ELT) tais como músicas, video clips, cenas de filmes, mas que tenham vínculo com o tema da unidade a que se refere e com a aula dada;

h) correção de exercício fora de sala com tabulação e análise de erros;

i) análise de provas ou testes;

j) elaboração de atividade de avaliação, com o devido gabarito. 
e-Mosaicos - Revista Multidisciplinar de Ensino, Pesquisa, Extensão e Cultura do Instituto de Aplicação Fernando Rodrigues da Silveira (CAp-UERJ) ANO 1 - V. 1 - N. 1 - JUNHO 2012 - ISSN: 2316-9303

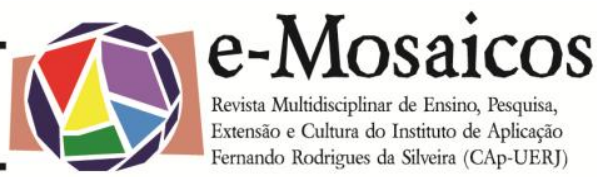

\section{Observações:}

$\left.1^{\mathrm{a}}\right)$ As atividades preparadas pelo estagiário deverão ser entregues ao professor orientador para reprodução com pelo menos uma semana de antecedência.

$2^{\mathrm{a}}$ ) O material didático elaborado pelo estagiário é um item para a avaliação do estágio. Não será, necessariamente, utilizado durante as suas (co-) participações.

Para cada uma das co-participações ou participações, o estagiário deverá apresentar ao professor orientador a ficha de avaliação de aula. Dessa ficha constam:

1) Identificação do Estagiário.

2) Dados referentes ao CAp-UERJ: turma/grupo, horário, professor(a) regente, data.

3) Identificação do material didático.

4) Habilidade(s) desenvolvida(s).

5) Etapas da aula implementadas: motivação, apresentação, prática oral, prática escrita, produção/ transferência, correção de exercícios, outros.

6) Análise do planejamento (exigido nas Práticas II e IV).

7) Desempenho do estagiário diante do grupo e ao elaborar o material didático, conforme o caso.

8) Objetivos atingidos.

9) Comentários adicionais e/ou sugestões. (MESMA COISA: OU LETRA MINÚSCULA OU (i))

10) Nota final.

Observação: Os dados a partir do item 3 são preenchidos pelo professor regente.
As pontuações dessas atividades de estágio foram aprovadas em reunião da equipe de docentes da disciplina de Língua Inglesa no CAp-UERJ, por unanimidade, devendo, portanto, ser cumpridas por todos os alunos-mestres inscritos nas quatro Práticas de Ensino, por ocasião do período de estágio correspondente às mesmas, em cumprimento ao previsto nas normas internas da Portaria de Estágio Supervisionado. Da mesma forma, a pontuação dessas atividades é decisão do professor orientador, e em acordo com a equipe de língua inglesa.

Todos os dados até aqui mencionados deverão ser incorporados ao Relatório, cujas normas foram estabelecidas pela equipe de docentes da disciplina de Língua Inglesa no CAp-UERJ, também por unanimidade, com base no que estabelece a ABNT. ${ }^{4} O$ Relatório tem caráter de um trabalho acadêmico.

\section{O QUE É UM RELATÓRIO}

Relatório é um documento de natureza técnico-científica, que se compõe da exposição de ocorrências ou da execução de serviços ou tarefas relacionadas a uma atividade específica. Convêm que sejam utilizados gráficos, mapas, tabelas, ilustrações etc. para ilustrar informações relativas às experiências adquiridas. Constitui-se um registro permanente de informações.

Segundo SILVA et alii (1974), THOMPSON (1991) e SALOMON (1996) são características de um relatório:

1 clara compreensão do assunto exposto;

2 dados e premissas adequados cuidadosamente julgados;

3 concatenação lógica da matéria;

4 equilíbrio na disposição e tamanho das

${ }^{4}$ Associação Brasileira de Normas Técnicas. 
e-Mosaicos - Revista Multidisciplinar de Ensino, Pesquisa, Extensão e Cultura do Instituto de Aplicação Fernando Rodrigues da Silveira (CAp-UERJ)

ANO 1 - V. 1 - N. 1 - JUNHO 2012 - ISSN: 2316-9303

partes;

5 correção gramatical: ortografia, pontuação e sintaxe (coesão e coerência);

6 uso de vocabulário impessoal;

7 utilização adequada dos recursos técnicos de redação.

\subsection{0 que se espera do Relatório de Estágio Supervisionado}

Esse, mais específico, revela um relato completo e objetivo do cumprimento do estágio no CAp-UERJ, funcionando como um trabalho acadêmico de final do curso de Prática de Ensino e Estágio Supervisionado em Língua Inglesa. Espera-se o relato e avaliação correta do trabalho desenvolvido pela equipe de Língua Inglesa na instituição supracitada. Propõe uma ponte entre a prática obtida no CAp-UERJ e os conhecimentos teóricos adquiridos na graduação, no ILE. Associa objetivos, meios e ações da atividade desenvolvida pela equipe de professores orientadores de Língua Inglesa com os resultados obtidos junto aos alunos dos ensinos fundamental e médio do CAp-UERJ.

O Relatório de Estágio Supervisionado deve ser uma contribuição ou observação relevante à área do ensino de Língua Inglesa no contexto político-ecnômico-social brasileiro e em conformidade com os PCNs ${ }^{5}$. É, antes de tudo, documentação técnicocientífica comprobatória do estágio, e ins-

\footnotetext{
${ }^{5}$ Parâmetros Curriculares Nacionais. Os Parâmetros Curriculares Nacionais - PCN - são referências de qualidade para os Ensinos Fundamental e Médio do país, elaboradas pelo Governo Federal. $\mathrm{O}$ objetivo é propiciar subsídios à elaboração e reelaboração do currículo, tendo em vista um projeto pedagógico em função da cidadania do aluno e uma escola em que se aprende mais e melhor.
}

trumento de análise e avaliação do estagiário, do processo de estágio, e da instituição onde o mesmo ocorreu.

\subsection{Estrutura do Relatório}

O plano de um Relatório de Estágio Supervisionado de Língua Inglesa deve seguir a seguinte ordem:

(i) Elementos de identificação: capa e folha de rosto

(ii) Índice (ou Sumário)

(iii) Sinopse

(iv) Introdução

(v) Desenvolvimento ou Corpo (dividido em capítulos ou seções)

(vi) Considerações finais (ou Conclusões)

(vii) Adendos e apêndices

(viii) Bibliografia (ou Referências Bibliográficas)

Constam da capa e da folha de rosto, que vem logo após a capa, os dados da instituição (nome da universidade, do centro setorial, do instituto básico onde o estagiário cursou a graduação), o curso de graduação, a disciplina de estágio, o título do relatório, o nome do estagiário, os nomes dos professores supervisor e orientador, a cidade, o ano e o semestre de elaboração do relatório.

A sinopse condensa o relatório em cerca de 200 palavras, utilizando um terço de página em papel A-4, alinhada à direita da base da página. A introdução apresenta 0 propósito, o alcance e o "background" do trabalho.

Quanto ao desenvolvimento ou corpo do trabalho, esse é dividido em capítulos e 
e-Mosaicos - Revista Multidisciplinar de Ensino, Pesquisa, Extensão e Cultura do Instituto de Aplicação Fernando Rodrigues da Silveira (CAp-UERJ)

ANO 1 - V. 1 - N. 1 - JUNHO 2012 - ISSN: 2316-9303

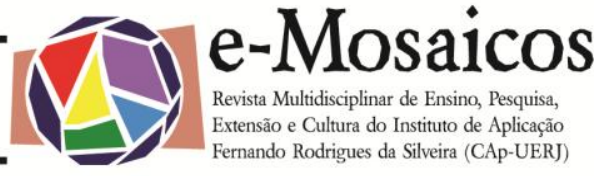

seções, ou apenas capítulos. O assunto é desenvolvido como um todo, evitando-se repetições, e relatando toda a experiência no CAp-UERJ desde o início das atividades, como a reunião de abertura, o encontro com o professor orientador, a escolha das turmas, entre outras. Também expressa as teorias a respeito dos mecanismos que governam as atividades de observação de aulas, co-participações e participações nas mesmas, sempre citando os autores estudados que embasam os fundamentos; interpreta os resultados das observações e participações; permite ao estagiário a expressão de suas opiniões pessoais, o desenvolvimento dos tópicos anunciados na introdução e a exposição e fundamento das conclusões a que chegou ao final do processo de estágio.

O desenvolvimento do Relatório deve explicar os seguintes itens:

(i) O Colégio de Aplicação: o espaço físico, a política pedagógica da Instituição, o perfil dos alunos etc

(ii) O estágio supervisionado

(iii) O papel do coordenador de estágio

(iv) 0 papel do professor orientador ${ }^{6}$

(v) O papel do professor supervisor ${ }^{7}$

(vi) $O$ papel do professor regente 8

(vii) As observações livres

(viii)As observações fixas

(ix) O material didático

\footnotetext{
${ }^{6}$ Professor orientador é o professor da turma em que o estagiário está co-participando ou participando (turma fixa).

7 Professor supervisor é o professor das disciplinas de Prática de Ensino e Estágio Supervisionado ministradas no Instituto de Letras.

${ }^{8}$ Professor regente é aquele que assume qualquer turma e não só o das observações livres.
}

(x) O suporte teórico-acadêmico (textos estudados nas aulas das disciplinas obrigatórias e eletivas)

(xi) As co-participações e as participações

(xii) O relacionamento estagiário 姜 professor orientador 姜 alunos

Quanto às considerações finais, o estagiário apresenta suas conclusões, recomendações e/ou sugestões para o trabalho, o agradecimento, a despedida, além de sintetizar as idéias expostas ao longo do corpo do trabalho.

Os adendos, apêndices ou anexos são as notas finais e adições ao texto elaborado pelo autor-estagiário. Entende-se que os apêndices se constituem material abonador ou documentador do Relatório; neste caso, a agenda de estágio (onde os professores orientadores assinam as atividades efetuadas pelos estagiários; as fichas de observação (em ordem cronológica, conforme a agenda de estágio), que são documentos preenchidos pelos estagiários, onde registram as atividades observadas nas aulas dos ensinos fundamental e médio; o(s) plano(s) de aula exigidos pelos professores orientadores; a(s) ficha(s) de avaliação, onde constam os registros feitos pelos professores orientadores em relação às atividades desenvolvidas pelos estagiários em suas turmas; as fichas de pesquisa de material para inglês instrumental; as cópias de todos os exercícios e atividades elaboradas pelo estagiário; o material ilustrativo; a lista bibliográfica ou de qualquer material de apoio (se for pertinente).

As regras gerais de apresentação da bibliografia (ou referências), notas de rodapé e citações no próprio texto são fornecidas aos estagiários nas instruções dadas aos estagiários no Manual do Estagiário. Envol- 
e-Mosaicos - Revista Multidisciplinar de Ensino, Pesquisa, Extensão e Cultura do Instituto de Aplicação Fernando Rodrigues da Silveira (CAp-UERJ)

ANO 1 - V. 1 - N. 1 - JUNHO 2012 - ISSN: 2316-9303

vem livros, artigos de periódicos (revistas, boletins etc), artigos de jornais, obras publicadas por Orgãos Governamentais e Entidades Coletivas e homepages institucionais.

Também são fornecidas aos estudantes as seguintes abreviaturas, frequentemente usadas em trabalhos acadêmicos:

$$
\begin{aligned}
& \text { cap. = capítulo } \\
& \text { Comp. = Compilador } \\
& \text { Coord. = Coordenador } \\
& \text { ed. = edição (Ex.: 3. ed.) } \\
& \text { Ed. = Editor } \\
& \text { eg = por exemplo (do latim exempli gratia) } \\
& \text { ibid = no mesmo local (latim ibidem) } \\
& \text { incl. = incluso } \\
& \text { n. = número } \\
& \text { N. B. = note bem } \\
& \text { Obs. = observação } \\
& \text { Org. = Organizador } \\
& \text { p. = página/páginas } \\
& \text { p. ex. = por exemplo } \\
& \text { s/d = sem data } \\
& \text { v. = volume/volumes } \\
& \text { v.g. = por amor da palavra; por exemplo } \\
& \text { (latim verbi gratia) } \\
& \text { viz. = convém ver (latim videlicet) }
\end{aligned}
$$

Cobra-se dos estagiários uma padronização da forma gráfica: texto, citações e notas, conforme posto a seguir:

1 Margem superior: $2,5 \mathrm{~cm}$

2 Margem inferior: 2,0 cm
3 Margem direita: $2,5 \mathrm{~cm}$

4 Margem esquerda: 3,0 cm

5 Entre linhas (espaço): 1,5, no texto, e simples, nas citações "fora do texto"

6 Fonte: Times New Roman

7 Numeração progressiva $(1,1.1,1.2$, 1.2.2, 2.2.1, etc) ou o uso de algarismos romanos, letras maiúsculas, minúsculas, números etc, para indicar as divisões e subdivisões sucessivas

8 Tamanho de fonte: 12 para o texto principal, 10 para citações e 8 para notas

9 Papel: A4 (210 X $297 \mathrm{~mm})$

No tocante à apresentação material do trabalho, exige-se que o Relatório seja encadernado em espiral. Os Relatórios de Estágio Supervisionado são arquivados na Sala de Estágio do CAp-UERJ com o objetivo de permitir a consulta desse material pelos professores do Departamento. O período de armazenamento desses relatórios é de 02 (dois) anos.

Os alunos serão avaliados com notas de 0 (zero) a 10 (dez), nas seguintes atividades:

1 Pela regência nas turmas, incluindo roteiros ou planos de aula, de acordo com a disciplina de Estágio;

2 Pela elaboração e apresentação oral e escrita de temas pertinentes nas aulas teóricas;

3 Pela elaboração do relatório final.

A Média Final será a média aritmética das notas: $M F=(R T)+(A T)+(R F) / 3$, 
e-Mosaicos - Revista Multidisciplinar de Ensino, Pesquisa, Extensão e Cultura do Instituto de Aplicação Fernando Rodrigues da Silveira (CAp-UERJ) ANO 1 - V. 1 - N. 1 - JUNHO 2012 - ISSN: 2316-9303

onde $\mathrm{MF}=$ média final, $\mathrm{RT}=$ nota pela regência de turmas, AT = nota decorrente dos trabalhos nas aulas teóricas e RF = relatório final.

\section{Considerações Finais}

O Relatório de Estágio Supervisionado deve, pois, ter uma posição típica entre os trabalhos acadêmicos: "relatar" a experiência do estagiário em toda sua dimensão, desde o planejamento, com o professor orientador, até as conclusões, porém de maneira concisa. Ao mesmo tempo, deve ser formulado visando ao destinatário: o professor supervisor, outros professores do Departamento, futuros estagiários etc.

Impossível determinar a extensão de um relatório dessa natureza. Dependerá de uma série de varáveis: do tipo de pesquisa que se desenvolveu e de seu objetivo, do grau de aprofundamento dos itens listados acima, ou do próprio estilo do estagiário. Recomenda-se, entretanto, que o total de páginas gire entre 40 e 50 .

Até o primeiro semestre de 2002, não havia propriamente nenhuma norma escrita para a elaboração de Relatório de Estágio Supervisionado em Língua Inglesa. Todas as orientações para esse fim eram passadas oralmente aos estagiários pelos professores supervisores ao longo das aulas teóricas. Os resultados, como era de se esperar, nem sempre eram uniformes: variavam desde simples exposições desordenadas das atividades desenvolvidas (algumas redigidas à mão em folhas de papel almaço) até relatos mais bem elaborados, dignos de se converterem em verdadeiras monografias.

A partir do segundo semestre de 2002, entretanto, pudemos constatar a evolução não só quantitativa (abrangência dos temas), mas também qualitativa (fidelidade e precisão dos fatos relatados) pelos estagiários, fruto de muitas reflexões e confrontos de diversos modelos ou abordagens sobre $o$ ensino de inglês como língua estrangeira para se chegar a uma definição de qual o mais indicado para atender satisfatoriamente aos objetivos da disciplina nas escolas em geral e nos Colégios de Aplicação em particular.

Acreditamos, assim, poder responder às necessidades desses futuros profissionais que desejam aprender a fazer um relatório de pesquisa ou de informes científicos e técnicos, que será, juntamente com outros componentes das disciplinas de estágio supervisionado, objeto de avaliação, focalizando:

a) o que deve conter um relatório;

b) técnicas práticas para elaboração e comunicação do relatório.

Esperamos, finalmente, que nossa iniciativa possa servir não necessariamente de modelo acabado, mas de estímulo aos outros Departamentos do CAp-UERJ para que no futuro venham a adotar procedimento semelhante com vistas à uniformização de critérios de avaliação dos estágios nas diferentes disciplinas.

\section{BibliOgRAFIA}

ASSOCIAÇÃO BRASILEIRA DE NORMAS TÉCNICAS. NBR 6023: Informação e documentação - Referências - Elaboração. Rio de Janeiro, 2002.

BARROS, Aidil Jesus da Silveira; LEHFELD, Neide Aparecida de Souza. Fundamentos de metodologia científica: um guia para a iniciação científica. 2. edição ampliada. São Paulo; Makron Books, 2000. 
e-Mosaicos - Revista Multidisciplinar de Ensino, Pesquisa, Extensão e Cultura do Instituto de Aplicação Fernando Rodrigues da Silveira (CAp-UERJ) ANO 1 - V. 1 - N. 1 - JUNHO 2012 - ISSN: 2316-9303

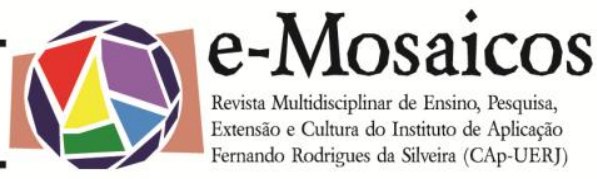

BIANCHI, Anna Cecilia de Moraes; ALVARENGA, Marina; BIANCHI, Roberto. Manual de Orientação: Estágio Supervisionado. 2. ed. São Paulo: Pioneira Thomson Learning, 2002.

BRASIL. Ministério da Educação. Retificação do Parecer CNE/CES 492/2001, que trata da aprovação das Diretrizes Curriculares Nacionais dos Cursos de Filosofia, História, Geografia, Serviço Social, Comunicação Social, Ciências Sociais, Letras, Biblioteconomia, Arquivologia e Museologia. PARECER N.O: CNE/CES 1363/2001 COLEGIADO: CES Brasília, 12/12/2001.

- Presidência da República. Lei $n^{\circ}$ 6.494, de 07 de dezembro de 1977. Dispõe sobre os estágios de estudantes de estabelecimento de ensino superior e de ensino profissionalizante do $2^{\circ}$ grau e Supletivo e dá outras providências. Brasília: Diário Oficial da União de 9.12.1977.

- Presidência da República. Decreto $n^{\circ}$ 87.497, de 18 de agosto de 1982. Regulamenta a Lei no 6.494, de 07 de dezembro de 1977, que dispõe sobre o estágio de estudantes de estabelecimentos de ensino superior e de $2^{\circ}$ grau regular e supletivo, nos limites que especifica e dá outras providências. Brasília: Diário Oficial da União de 19.8.1982.

. Secretaria de Educação Fundamental. Parâmetros Curriculares Nacionais: terceiro e quarto ciclos de ensino fundamental: língua estrangeira / Secretaria de Educação Fundamental. Brasília: MEC/SEF, 1998.

Conselho Nacional de Educação. Parecer CNE/CES 492/2001. Diretrizes Curriculares Nacionais dos cursos de Filosofia, História, Geografia, Serviço Social, Comunicação Social, Ciências Sociais, Letras, Biblioteconomia, Arquivologia e Museologia. Braślia: Diário Oficial da União de 09/7/2001,
Seção le p. 50.

Conselho Nacional de Educação. Resolução CNE/CP no 01 de 19/02/2002. Institui as Diretrizes Curriculares Nacionais para a Formação de Professores da Educação Básica, em nível superior, curso de licenciatura, de graduaçãa plena. Brasília: Diário Oficial da União de 04.3.2002.

- Conselho Nacional de Educação. Resolução CNE/CP no 02 de 19/02/2002. Institui a duração e carga horária dos cursos de licenciatura, de graduação plena, de formação de professores de Educação Básica em nível superior. Brasília: Diário Oficial da União de 04.3.2002.

CARVER, Ronald P. Writing a publishable research report: in education, psychology, and related disciplines. Springfield, Illinois: Charles C Thomas, 1984.

CURTO, Josephine J. Writing technical reports. 5. ed. Middlessex: Penguin, 1971. DEMO, Pedro. Professor do futuro e reconstrução do conhecimento. Petrópolis: Vozes, 2000.

HIRANO, Sedi (org.). Pesquisa social: projeto e planejamento. São Paulo: T. A. Queiroz, 1979.

HOUAISS, Antônio. Elementos de bibliologia. Rio de Janeiro: MEC, Instituto Nacional do Livro, 1967.

MINSTÉRIO DA EDUCAÇÃO/SECRETARIA DE EDUCAÇÃO BÁSICA. Orientações curriculares para o ensino médio: linguagens, códigos e suas tecnologias, volume 1. Brasília: Ministério d a Educação; Secretaria de Educação Básica, 2006.

SALOMON, Délcio Vieira. Como fazer uma monografia: elementos de metodologia do trabalho científico. 4. ed. São Paulo: Martins Fontes, 1996.

SEVERINO, Antônio Joaquim. Metodologia 
e-Mosaicos - Revista Multidisciplinar de Ensino, Pesquisa, Extensão e Cultura do Instituto de Aplicação Fernando Rodrigues da Silveira (CAp-UERJ)

ANO 1 - V. 1 - N. 1 - JUNHO 2012 - ISSN: 2316-9303

do trabalho cientifico: diretrizes para o trabalho científico-didático na universidade. 5 . ed. São Paulo; Cortez \& Moraes, 1980.

SILVA, Rebeca Peixoto da et alii. Redação técnica. Porto Alegre: Formação, 1974.

SPENCER Carolyn M.; ARBON, Beverly. Foundations of writing: developing research and academic skills. Lincolnwood, Illinois: and academic skills. Lincolnwood, Illinois:
National Textbook Company, 1996.

1 joao.bittencourt@bol.com.br - Graduado em Português-Inglês pela Universidade do Estado do Rio de Janeiro (1974), atualização em Literatura Norte-Americana Contemporânea "Contemporary American Novels" pela Universidade Federal do Rio de Janeiro (1976), Especialização em Linguística Aplicada ao Ensino de Língua Inglesa pela Universidade Federal Fluminense (1985) e Mestrado em Letras (Língua Inglesa) pela Universidade Federal Fluminense (1988). Professor Assistente da Universidade do Estado do Rio de Janeiro / Instituto de Aplicação da Universidade do Estado do Rio de Janeiro - CAp-UERJ. Membro do Círculo Fluminense de Linguística e Filologia. Desenvolve pesquisas nas áreas de Linguística e Letras, com ênfase nas subáreas de Linguística Aplicada ao Ensino de Língua Inglesa, atuando principalmente no ensino das seguintes disciplinas: língua inglesa, enfoques metodológi$\cos$ no ensino de língua inglesa, inglês instrumental, linguística aplicada ao ensino de língua inglesa e gêneros textuais no ensino de língua inglesa.

2 martacaram@hotmail.com - Graduada em Letras / Português-Inglês pela Universidade Santa Úrsula (1982) e Mestrado em Linguística Aplicada pela Universidade Federal do Rio de Janeiro (1996). É aposentada como Professor I pela Secretaria Municipal de Educação do Rio de Janeiro e atua como Professora Assistente da Universidade do Estado do Rio de Janeiro / Instituto de Aplicação Fernando Rodrigues da Silveira CAp-UERJ. Tem experiência na área de Letras, com ênfase em Língua Inglesa, atuando principalmente na licenciatura (formação de docentes e estágio) e ensino de leitura. Atualmente é coordenadora de estágio no Instituto de Aplicação Fernando Rodrigues da Silveira - CAp-UERJ. 